\title{
Avaliação dos \\ Trabalhadores acerca de um Programa de Qualidade de Vida no Trabalho: Validação de Escala e Análise Qualitativa
}

\author{
Evaluation Of Workers About A Program Of Quality \\ Of Life At Work: Validation Of Scale And Qualitative \\ Analysis
}

Evaluación De Los Trabajadores Acerca De Un Programa De Calidad De Vida En El Trabajo: Validación De Escala Y Análisis Cualitativo

Polyanna Peres Andrade Universidade de Brasília

Heila Magali da Silva Veiga Universidade Federal de Uberlândia

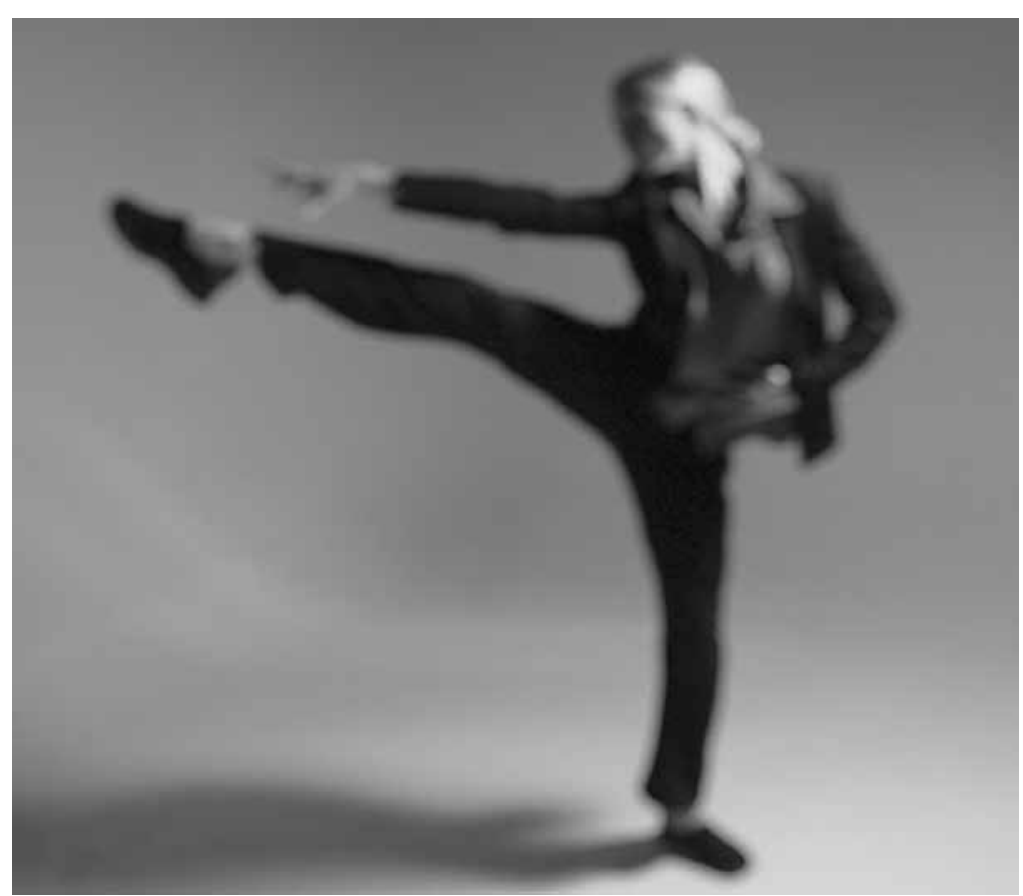


Resumo: A presente pesquisa teve como objetivo geral analisar a percepção dos gestores, servidores e estagiários acerca das ações do Programa de Qualidade de Vida no Trabalho (PQVT) de um órgão público. Para tanto, foram realizados três estudos, sendo um quantitativo e dois qualitativos. No primeiro deles, foi construída e validada uma escala para avaliar a ginástica laboral, principal atividade do programa, a qual foi aplicada a uma amostra de conveniência de 623 trabalhadores. A análise fatorial dos eixos principais com rotação promax indicou a existência de quatro fatores: professores ( $\alpha=0,89,7$ itens), relacionamento entre os colegas ( $\alpha=0,77,5$ itens), benefícios da ginástica laboral ( $\alpha=0,74,5$ itens) e método de trabalho $(\alpha=$ 0,58, 4 itens). O segundo estudo foi realizado com 21 estagiários do PQVT e mostrou que estes percebem que sua participação nas ações do programa auxilia em sua formação profissional. O terceiro foi realizado com gestores e servidores, e revelou que ambos conhecem e valorizam todas as ações do programa, contudo, pontuam a excessiva demanda de trabalho e a falta de infraestrutura como lacunas do mesmo. Os resultados dos estudos quantitativo e qualitativo foram complementares, e os achados, discutidos à luz da teoria.

Palavras-chave: Qualidade de vida no trabalho. Condições de trabalho. Validação da escala. Pesquisa qualitativa.

\begin{abstract}
The objective of this research was to examine the perception of managers, workers and trainees about the actions of the Program of Quality of Life at Work (QVT) of a public organization. To this end, three studies were undertaken, a quantitative and two qualitative. In the first of them a scale to assess the perception or workers about the stretch-break, the main activity of the QVT program, was built and validated. The instrument was applied to a convenience sample of 623 workers. The factor analysis with rotation promax indicated the existence of four factors: teachers $(\alpha=0.89,7$ items), the relationship between workers $(\alpha$ $=0,77,5$ items), the labor benefits of stretch-break ( $\alpha=0.74,5$ items) and the method of work $(\alpha=0,58$, 4 items). The second study conducted with trainees showed that they realize that their participation in the program assists actions in their vocational training. A third one held with managers and workers showed that they know and value all the actions of the program, however, excessive labor demand and lack of infrastructure were seen as gaps. The results of the quantitative and qualitative studies and findings were discussed in the light of the theory.
\end{abstract}

Keywords: Quality of working life. Condition working.Validation of scale. Qualitative research.

Resumen: La presente investigación ha tenido como objetivo general analizar la percepción de los gestores, servidores y de estudiantes en prácticas acerca de las acciones del Programa de Calidad de Vida en el Trabajo (PCVT) de un órgano público. Para tanto, se han llevado a cabo tres estudios: un cuantitativo y dos cualitativos. En el primero de ellos, ha sido construida y validada una escala para evaluar la gimnasia laboral, principal actividad del programa, la cual ha sido aplicada a una muestra de conveniencia de 623 trabajadores. El análisis factorial de los ejes principales con rotación promax ha señalado la existencia de cuatro factores: profesores ( $\alpha=0,89,7$ ítems), relacionamiento entre los compañeros de trabajo $(\alpha=0,77$, 5 ítems), beneficios de la gimnasia laboral ( $\alpha=0,74,5$ ítems) y método de trabajo ( $\mathrm{a}=0,58,4$ ítems). El segundo estudio ha sido llevado a cabo con 21 estudiantes en prácticas del PCTV y ha demostrado que éstos se dan cuenta de que su participación en las acciones del programa auxilia en su formación profesional. El tercero ha sido llevado a cabo con gestores y servidores, y ha revelado que ambos conocen y valoran todas las acciones del programa. Sin embargo, señalan la excesiva demanda de trabajo y la falta de infraestructura, como huecos en él. Los resultados de los estudios cuantitativo y cualitativo han sido complementarios, y los hallazgos, discutidos a la luz de la teoría.

Palabras clave: Calidad de vida del trabajo. Condiciones del trabajo. Validacion de la escala. Investigación cualitativa.

O atual contexto organizacional está cada dia mais competitivo devido às constantes e diversas mudanças no cenário econômico, político, tecnológico, social e cultural. Para adaptar-se a essa realidade, as empresas estão se atualizando e investindo em seus processos de trabalho para manterem-se competitivas. Considerando que os trabalhadores são fundamentais nesse processo, há uma pressão para a excelência do desempenho e do alcance de metas e por resultados satisfatórios. Assim, a preocupação com o ser humano no seu ambiente de trabalho tem sido uma constante em várias pesquisas e nas organizações, por meio de ações que privilegiam a saúde do trabalhador.

A qualidade de vida no trabalho (QVT) está relacionada a preocupações com o estresse e à forma de evitá-lo, à busca de satisfação no trabalho, à importância da Saúde Mental e à necessidade de garanti-la no ambiente 
laboral (Monteiro, Maus, Machado, Pesenti, Bottega, \& Carniel, 2007) e como forma para humanizar o trabalho (Pilatti \& Bejarano, 2005). Os programas de qualidade de vida no trabalho (PQVT) subsidiam atividades que favorecem a prevenção e a promoção da saúde, atendendo as necessidades mais amplas do trabalhador, sendo assim, buscam conciliar o interesse dos empregados e da organização, ressaltando-se que as organizações que não têm a QVT como um de seus objetivos organizacionais correm o risco de desaparecer (Limongi-França \& Zaima, 2002). Ressalta-se, porém, que os PQVT não devem se restringir apenas às atividades relacionadas com o bem-estar (Ferreira, Ferreira, Antloga, \& Bergamaschi, 2009).

A qualidade de vida no trabalho (QVT) é uma preocupação crescente e fundamentada das organizações que buscam alta competitividade em mercados cada vez mais globalizados. O período em que se deu início às primeiras pesquisas em QVT aparece na literatura de forma não consensual. Os primeiros programas de segurança no trabalho surgem nas décadas de 30 e 40, e, na década de 50, Eric Trist e seus colaboradores são apontados como precursores das pesquisas por terem proposto o primeiro modelo de QVT (Fernandes, 1996). Somente a partir da década de 60 é que os estudos ganharam impulso, com maior preocupação com o bem-estar dos trabalhadores (Tolfo \& Piccinnini, 2001). Fernandes e Gutierrez (1988) afirmam que, nas décadas de 70 e 80, foram desenvolvidos diversos modelos acerca das condições que interferem no desempenho humano nas organizações, como os de Walton (1973), Hackman e Oldham (1975), Nadler e Lawler (1983) e os de Werther e Davis (1983).

A despeito do interesse pelo estudo da qualidade de vida no trabalho (QVT) ter surgido há algumas décadas, não há consenso acerca de sua definição. Além disso, pode ser concebida como uma variável, um método ou uma abordagem (Fernandes \& Gutierrez, 1988). Nas diversas definições, porém, verificase que há um movimento de reação ao rigor dos métodos tayloristas e, em consequência, um instrumento que objetiva maior humanização no trabalho, participação nas decisões, melhoria do ambiente de trabalho e inovações no sistema de recompensas (Nadler \& Lawler, 1983).

Guimarães (1998) destaca que essa variabilidade de concepção está associada à interpretação acerca do que seja a QVT, que pode ser mais ou menos ampla. Uma visão mais restrita compreende a QVT como método de assepsia ambiental com ênfase nos aspectos ergonômicos do trabalho, ou simplesmente nas atividades de saúde física e ocupacional dos trabalhadores, que é uma visão reducionista (Mônaco \& Guimarães, 2000). A outra concepção é mais humanista e ampla, inclui uma interpretação socio-política e considera a participação do trabalhador uma variável central. Nessa perspectiva, diversas ciências trazem contribuição relevante ao seu estudo, como saúde, Ecologia, ergonomia, Psicologia, Sociologia, Economia, Administração e Engenharia (Vasconcelos, 2001).

Ferreira, Ferreira, Antloga e Bergamaschi (2009) dividem os modelos de investigação da qualidade de vida no trabalho em dois momentos, um assistencialista e outro contrahegemônico. No primeiro, há destaque para as atividades de bem-estar físico com o objetivo de compensar o desgaste dos trabalhadores na busca pela produtividade. $\mathrm{Na}$ abordagem contra-hegemônica, o foco está no aspecto preventivo, em remover os aspectos causadores de mal-estar no trabalho nas três dimensões interdependentes, condições, organização e relações socio-profissionais. Assim, a produtividade passa a ser uma consequência, e não o objetivo central dos programas de QVT. 
Como forma

de controle do stress, Lipp,

Malagris e Novais (2007) apontam

quatro pilares: alimentação saudável e equilibrada, relaxamento, prática regular e sistemática de exercícios físicos e reestruturação cognitiva, que parte da

hipótese de que pensamentos geram sentimentos, e assim os pensamentos distorcidos e negativos devem ser substituídos por pensamentos mais funcionais para o bem-estar do indivíduo.

Albuquerque e Limongi-França sustentam que a

\begin{abstract}
"qualidade de vida no trabalho é um conjunto de ações de uma empresa que envolve diagnóstico e implementação de melhorias e inovações gerenciais, tecnológicas e estruturais dentro e fora do ambiente de trabalho, visando a propiciar condições plenas de desenvolvimento humano para e durante a realização do trabalho" (1997, p. 41)
\end{abstract}

Segundo Ferreira (2006), o conceito de QVT engloba duas perspectivas interdependentes: a ótica dos dirigentes e gestores, que traz as normas, diretrizes e práticas que visam à promoção do bem-estar individual e coletivo, o desenvolvimento pessoal dos trabalhadores e o exercício da cidadania organizacional, e a ótica dos trabalhadores, com as representações que estes constroem da organização na qual estão inseridos, que indicam o predomínio de vivências de bem-estar no trabalho, de reconhecimento institucional e coletivo, de possibilidade de crescimento profissional e de respeito às características individuais. O bem-estar e o mal-estar são representações mentais dos trabalhadores referentes ao estado geral em determinados momentos e contextos. As representações de bem-estar consistem em avaliações positivas que os trabalhadores fazem sobre seu estado físico, psicológico e social relativos ao contexto de produção em que estão inseridos. O mal-estar, por sua vez, corresponde às representações mentais negativas que os trabalhadores formulam sobre esses mesmos estados e sobre o contexto de trabalho.

A partir das definições encontradas, verificase que qualidade de vida no trabalho vai além de práticas específicas deliberadas apenas pelas pessoas com cargo gerencial. Pode-se afirmar que QVT é tarefa de todos e responsabilidade organizacional.
Ao se implementar um programa de qualidade de vida no trabalho, deve ser feito um processo de diagnóstico organizacional e uma implementação cuidadosa e teoricamente embasada, para que se obtenha um aumento da produtividade e da satisfação dos colaboradores. Além disso, a participação efetiva dos trabalhadores nas decisões é um requisito essencial (Guimarães, 1998).

O estudo ora relatado surgiu da necessidade de avaliação das atividades do Programa de Qualidade de Vida no Trabalho (PQVT) do Ministério da Saúde (MS) em Brasília - DF. Esse programa oferece uma série de atividades, como ginástica laboral e aulas de dança e yoga, sendo a primeira atividade a principal. Lima (2004) define a ginástica laboral como a prática de exercícios, feita coletivamente durante o expediente de trabalho, os quais são prescritos de acordo com a função exercida pelo trabalhador e que têm como objetivo a prevenção de doenças ocupacionais e a promoção do bem-estar.

Considerando a demanda da organização, o objetivo central do estudo é analisar as percepções que os trabalhadores, os gestores e os estagiários têm em relação às ações desenvolvidas no PQVT. Para o alcance do objetivo geral, foram realizados três estudos: o primeiro é quantitativo e tem a finalidade de construir e validar uma medida de percepção dos trabalhadores acerca da prática da ginástica laboral (GL) e aplicá-la a uma amostra representativa da organização; o segundo e o terceiro são qualitativos, e têm como finalidade investigar (1) as percepções dos estagiários de educação física acerca das atividades de GL propostas e conduzidas por seus supervisores e (2) verificar como os gestores e servidores avaliam todas as ações do programa. 


\section{Estudo 1 - Pesquisa quantitativa a construção da escala}

\section{A organização}

O Ministério da Saúde (MS) foi criado pela Lei no 1.920, de 25 de julho de 1953, para resolver os problemas de competência federal atinentes à saúde humana. Atualmente, o Ministério da Saúde tem como área de competência os seguintes assuntos: política nacional de saúde, coordenação e fiscalização do sistema único de saúde - SUS, saúde ambiental e ações de promoção, proteção e recuperação da saúde individual e coletiva, inclusive a dos trabalhadores e dos índios, informações de saúde, insumos críticos para a saúde, ação preventiva em geral, vigilância e controle sanitário de fronteiras e de portos marítimos, fluviais e aéreos, vigilância de saúde, especialmente quanto às drogas, medicamentos e alimentos, e pesquisa científica e tecnológica na área de saúde.

O Decreto № 6.860, de 27 de maio de 2009, aprovou a Estrutura Regimental e o Quadro Demonstrativo dos Cargos em Comissão e das Funções Gratificadas do Ministério da Saúde que se constitui basicamente de cinco secretarias finalísticas, o Gabinete do Ministro, a Consultoria Jurídica e a Secretaria-Executiva, além do Conselho Nacional de Saúde, o Conselho de Saúde Suplementar e as entidades vinculadas.

O referido órgão possui aproximadamente 3000 trabalhadores, lotados em diferentes unidades pelo Brasil. O Programa de Qualidade de Vida no Trabalhoé denominado Programa Geração Saúde, e foi elaborado e construído pelos servidores do MS ao longo da última década, através de uma pesquisa informal corpo a corpo denominada Caça Talentos, realizada em todos os níveis hierárquicos do MS. O resultado da pesquisa deixou evidente a necessidade de se criar atividade que melhorasse a disposição dos servidores da casa e, ainda, que fortalecesse os grupos, aproveitando os talentos dos servidores do MS. A coordenação do PQVT está sob a responsabilidade da Coordenação de Planejamento e Desenvolvimento de Recursos Humanos, que integra a estrutura da Coordenação Geral de Recursos Humanos da Subsecretaria de Assuntos Administrativos da Secretaria-Executiva do MS. O modelo de QVT adotado no MS se aproxima mais do assistencialista, pois privilegia ações pontuais de caráter compensatório dos desgastes ocasionados pelo trabalho.

\section{Construção da medida}

Para a construção do instrumento, foram conduzidas entrevistas com coordenadores do Programa de Qualidade de Vida no Trabalho da organização, com servidores de diferentes secretarias e com profissionais de educação física (responsáveis pela condução da ginástica laboral). A análise das informações permitiu a criação de cinco fatores: características dos professores, benefícios físicos e mentais da ginástica laboral, expectativa do servidor, integração entre os participantes e método de trabalho. Para cada um dos fatores, foi elaborada uma definição constitutiva e operacional.

A partir das definições dos fatores, foram construídos 10 itens para cada, que foram submetidos às análises semântica e dos juízes, conforme orientação de Pasquali (2005). A análise semântica da pesquisa foi feita com oito sujeitos, sendo dois do sexo feminino com formação superior completa e seis do sexo masculino, sendo um com formação superior incompleta e os demais com formação superior completa. Durante a análise semântica, a pesquisadora leu item por item para cada participante e questionou a sua compreensibilidade. Para a realização da análise de juiz, foi solicitado 
a uma professora universitária da área de Psicologia organizacional e a uma psicóloga da área organizacional que avaliassem o pertencimento de cada item a um dos cinco fatores. Com base em tais análises, os itens que apresentaram problemas de compreensão ou de não pertencimento ao fator foram eliminados, o que resultou em um total de 30 itens.

\section{Método}

\section{Amostra}

A população de servidores inscritos na ginástica laboral do Programa Geração Saúde é formada por um total de 1384 trabalhadores. Para essa pesquisa, foi utilizada uma amostra não probabilística de conveniência. Foram distribuídos 700 questionários, dos quais 665 foram devolvidos, o que equivale a uma taxa de retorno de 95\%. Após inspeção e análise do banco de dados, a amostra final ficou composta por 623 trabalhadores, o que corresponde a $45,01 \%$ da população.

\section{Instrumento}

A Escala para Avaliação de Ginástica Laboral (EPAGL) é formada por 30 itens, sendo oito itens referentes ao fator professores, cinco itens, ao fator benefícios da ginástica laboral, seis itens, ao fator expectativa do servidor, seis itens, ao fator integração, e cinco itens, ao fator método de trabalho atual. Foi utilizada uma escala de resposta do tipo Likert de cinco pontos, sendo: (1) discordo totalmente, (2) discordo, (3) nem discordo e nem concordo, (4) concordo e (5) concordo totalmente.

\section{Procedimento e análise de dados}

A aplicação dos instrumentos foi feita de forma individual por estagiários de educação física que ministram a ginástica laboral e pela primeira autora. Durante o preenchimento do questionário, os aplicadores se disponibilizavam a auxiliar no esclarecimento de dúvidas. Em média, as pessoas demoravam de 15 a 20 minutos para responder as questões da escala.

Para a análise dos dados, foi utilizado o programa SPSS versão 15.1 para a realização de estatísticas descritivas e inferenciais e análise fatorial.

\section{Resultados}

A validade de construto da Escala de Avaliação de Ginástica Laboral foi verificada através da análise fatorial. Primeiramente, procedeu-se à análise dos componentes principais para avaliar a fatorabilidade da matriz dos dados. O KMO foi de 0,94, e o Teste de Esfericidade de Bartlett, significativo $(6761,435 p<0,001)$. A inspeção do scree plot indicou a presença de quatro fatores (vide Figura 1), e, ao considerar eigenvalue superior a 1 , deveriam ser extraídos quatro fatores, e, pelo modelo hipotetizado, cinco fatores. Assim, as autoras optaram por extrair 3, 4 e 5 fatores utilizando análise fatorial com rotação promax e por avaliar a interpretabilidade das soluções. A solução de quatro fatores apresentou os melhores resultados, e os itens revelaram consistência teórica.

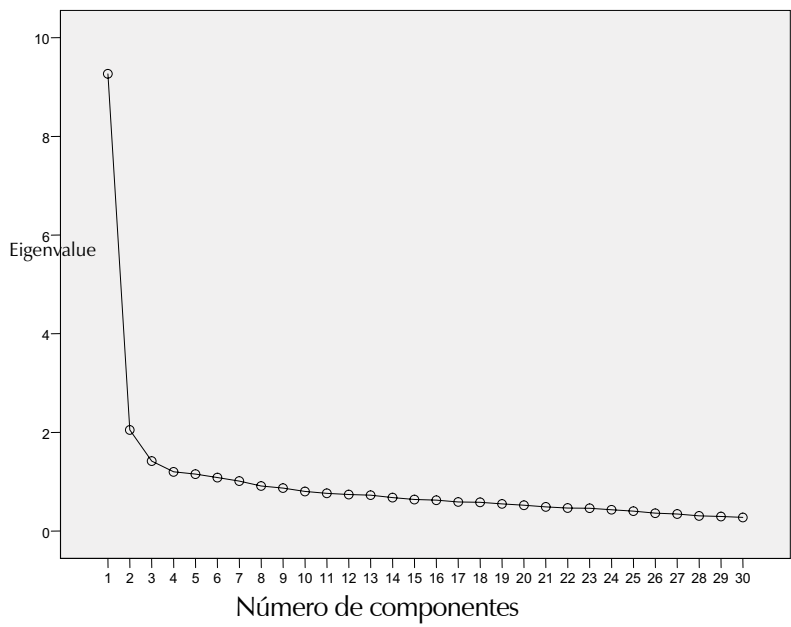

Figura 1. Scree Plot 
A variância total explicada pelos quatro fatores foi de 46,44\%. A Tabela 1 apresenta os itens de cada fator, a variância explicada de cada um deles e o índice de confiabilidade (alfa de Cronbach). O primeiro fator é formado por sete itens, e foi denominado professores. O segundo fator é formado por cinco itens, e diz respeito à integração entre os colegas de trabalho; o terceiro fator também possui cinco itens, e trata dos benefícios oriundos da prática da ginástica laboral. Por fim, o quarto fator compreende quatro itens, e mede a metodologia usada na ginástica laboral. A Tabela 2 apresenta os fatores e suas definições.

Tabela 1. Cargas fatoriais, variância explicada e fidedignidade da EPAGL

\begin{tabular}{ll}
\hline Item & Fato \\
\hline 25. Professor domina conteúdo GL & 0,81 \\
29. Criatividade no planejamento das atividades & 0,74 \\
7. Os(as) professores(as) estimulam a turma & 0,74 \\
26. Professores usam comunicação clara e objetiva & 0,72 \\
12. Disposição para esclarecer as dúvidas & 0,65 \\
16. Pontualidade do professor & 0,56 \\
19. Metodologia adequada do professor (a) & 0,54
\end{tabular}

11. Relacionamento com os colegas $\quad 0,67$

5. Interesse por outras atividades físicas $\quad 0,60$

6. Colegas de trabalho mais espontâneos após GL 0,53

1. GL como momento de integração $\quad 0,46$

4. Melhoras no desempenho profissional após GL $\quad 0,35$

28. A GL promove a sensação de bem-estar

$\begin{array}{ll}\text { para a jornada de trabalho } & 0,60\end{array}$

8. A GL é mais eficiente sendo realizada

todos os dias $\quad 0,54$

14. A GL é um momento de descontração $\quad 0,52$

10. Disposição pós GL $\quad 0,45$

9. Sinto-me satisfeito com a prática da GL $\quad 0,41$

$\begin{array}{ll}\text { 17. Tempo das aulas adequado } & 0,63\end{array}$

3. Ergonomia do ponto de GL $\quad 0,41$

$\begin{array}{ll}\text { 20. Músicas } & 0,32 \\ 23 . \text { Recebo feedback sobre atividades GL } & 0,30\end{array}$

23. Recebo feedback sobre atividades GL $\quad 0,30$

$\begin{array}{llccc}\text { Variância explicada } & 30,89 \% & 6,83 \% & 4,72 \% & 3,99 \% \\ \text { Número de itens } & 7 & 5 & 5 & 4 \\ \text { Coeficiente de fidedignidade (alfa de Cronbach) } & 0,89 & 0,77 & 0,74 & 0,58\end{array}$

*Itens abreviados, que expressam apenas a ideia central. 
Tabela 2. Fatores da escala e suas definições

Nome do fator

1. Características dos professores

2. Relacionamento entre os colegas

3. Benefícios da ginástica laboral

4. Método de trabalho

\section{Definição}

Nesse fator, é avaliado o empenho, a disposição e a prontidão dos professores durante as atividades de ginástica laboral.

Verifica se o trabalho dos professores promove ações que visam à integração, além de investigar qual é o papel da ginástica laboral no desempenho profissional.

Investiga se as expectativas com relação à qualidade do serviço prestado ou à efetividade das atividades em suas vidas estão sendo alcançadas.

Aborda questões como: o espaço físico em que a GL é ministrada (salas, corredor, hall do elevador), a duração das seções e as músicas.

Na Tabela 3, pode-se observar que, dos fatores avaliados, a maior média foi encontrada em benefícios da ginástica laboral, o que mostra que os trabalhadores percebem as mudanças oriundas da participação. Em contrapartida, o aspecto pior avaliado diz respeito ao método de trabalho, que compreende questões relacionadas com a qualidade da ginástica laboral.

Tabela 3. Fatores da escala

\begin{tabular}{llll}
\hline Fator & Média & Moda & Desvio-padrão \\
\hline Características dos professores & 4,00 & 4,00 & 0,69 \\
Integração com os colegas & 3,95 & 4,00 & 0,65 \\
Benefícios da ginástica laboral & 4,43 & 5,00 & 0,51 \\
Método de trabalho & 3,67 & 4,00 & 0,80 \\
\hline
\end{tabular}

A Tabela 4 apresenta os resultados da correlação entre os fatores da escala. Verifica-se que a maior correlação encontrada foi entre os fatores integração com os colegas e benefícios $(r=0,616$; $p<0,01)$. Também foram encontradas correlações moderadas entre os fatores professores e integração com os colegas $(r=0,592 ; p<0,01)$. Os fatores que apresentaram índice de correlação mais baixo foram benefícios da GL e método de trabalho atual $(r=0,371 ; p<0,01)$. 
Tabela 4. Correlação dos fatores da escala

\begin{tabular}{lllll}
\hline & 1 & 2 & 3 & 4 \\
\hline 1. Características do professor & 1 & $0,571^{* *}$ & $0,592^{* *}$ & $0,507^{* *}$ \\
2. Integração com os colegas & & 1 & $0,616^{* *}$ & $0,371^{* *}$ \\
3. Benefícios da ginástica laboral & & & 1 & $0,401^{* *}$ \\
4. Método de trabalho & & & 1 \\
\hline$* * p<00,1$ & & &
\end{tabular}

Os resultados da pesquisa quantitativa mostram que a escala construída apresenta consistência teórica e empírica e que a confiabilidade dos fatores é satisfatória, o que significa que se tem uma medida adequada da percepção dos trabalhadores acerca da ginástica laboral.

\section{Estudo 2 - Pesquisa qualitativa com estagiários}

As atividades do Programa de Qualidade de Vida no Trabalho eram conduzidas por estagiários de educação física e supervisionadas por profissionais da área.

\section{Amostra}

Participaram deste estudo todos os 21 estudantes que atuavam no PQVT. Eles tinham entre 22 e 28 anos de idade, cursavam do $4^{\mathrm{O}}$ ao $8^{\mathrm{o}}$ semestre e estagiavam de três meses a dois anos na empresa.

\section{Instrumento}

1. Para a coleta de dados do grupo de estagiários, elaborou-se um questionário com duas questões abertas, possibilitando que eles expressassem sua percepção acerca da importância de suas atividades, bem como das possibilidades para melhoria de suas ações. As questões adotadas foram: (1) Qual o papel do estagiário no Programa Geração Saúde? e (2) O que eu posso fazer para melhorar como estagiário?

\section{Procedimento de coleta e análise de dados}

Foi acordado com a coordenação do programa e com os supervisores de estágio que os estudantes teriam um dia destinado ao preenchimento do questionário. A aplicação foi feita em uma sala de reuniões, individualmente, e o tempo de execução da atividade foi de aproximadamente 20 minutos.

\section{Resultados}

As respostas dos estagiários foram agrupadas em sete fatores que tratam da sua percepção acerca do papel que desempenham no Programa Geração Saúde.

Conforme apresentado na Tabela 5, verifica-se que os fatores 1. aprimoramento e busca de conhecimento, 2. desenvolvimento de um trabalho de qualidade e 3. crescimento pessoal e profissional apresentaram as maiores frequências: 21, 19 e 19, respectivamente, enquanto o fator sete, planejamento das aulas e assiduidade, obteve a frequência mais baixa, 6 . 
Tabela 5. Percepção dos estagiários com relação ao seu papel no PGS

Fator
1.Aprimoramento e busca de
conhecimento
2.Desenvolver um trabalho de qualidade

3.Incentivar e orientar os servidores

4.Relacionamento interpessoal

5.Promover qualidade de vida

6.Contribuir para o crescimento do programa

7.Planejamento das aulas e assiduidade
Exemplo de fala

"Estar me atualizando cada dia

Frequência

mais e buscar o conhecimento

prático/teórico".

"Desenvolver um trabalho de qualidade para maior satisfação dos clientes".

"Incentivar as pessoas que participam do programa mostrando a sua importância para a busca de uma vida saudável não somente no trabalho mas também para a vida".

"Trabalhar a integração entre os próprios funcionários e no nosso ambiente de trabalho (estagiários), melhorar o relacionamento com os colegas e ajudar os outros sempre que preciso".

"Através de seu conhecimento profissional, juntamente à orientação dos coordenadores, proporcionar melhor qualidade de vida dos clientes, tanto no trabalho quanto pessoal".

“Fazer com que o programa seja 8 reconhecido e aceito por todo o público do Ministério da Saúde".

"Preparar as aulas com mais 6 antecedência (planejamento) e não faltar às aulas de laboral, aconselhar os demais colegas estagiários que faltam às aulas". 


\section{Estudo 3- Pesquisa qualitativa com gestores e trabalhadores}

\section{Amostra}

Fizeram parte do segundo grupo seis sujeitos escolhidos aleatoriamente, todos do sexo feminino, sendo três coordenadoras de setor e três servidoras. Para cada um dos entrevistados, foi atribuído um nome fictício. A primeira participante foi Helena, 40 anos, está há 15 no Ministério da Saúde, mas que há menos de um ano exerce a função de coordenadora. A servidora entrevistada de seu setor foi Patrícia, 28 anos, é terceirizada e trabalha há sete anos no Ministério. Em seguida, foram entrevistadas Édina, 63 anos, servidora há 8 e coordenadora há 3 anos, e Joana, 59 anos, servidora efetiva há 24 anos. Por fim, participaram da pesquisa Cláudia, 46 anos, coordenadora, que está na instituição desde 2001, e Bruna, 40 anos, que há 18 anos trabalha na instituição.

\section{Instrumento}

Em vista da diferença dos cargos e das atribuições das participantes do grupo, foram elaborados dois modelos diferentes de roteiro de entrevista, semiestruturados, com perguntas abertas para que as entrevistadas pudessem relatar suas experiências e percepções acerca do PQVT. Para a construção destes, foram levadas em consideração questões relacionadas à participação nas atividades disponibilizadas, interesse pelo programa, interação com colegas de sala e equipe do PQVT e, ainda, os benefícios decorrentes das atividades.

\section{Procedimento de coleta e análise de dados}

Primeiramente, os colaboradores leram e assinaram um Termo de Consentimento Livre e Esclarecido acerca da pesquisa e de seus procedimentos antes de responderem as perguntas propostas e de exporem sua opinião sobre o assunto. As entrevistas foram feitas de maneira individual, em ambiente reservado, dentro dos diferentes setores visitados, e todas elas foram gravadas em MP4 para que posteriormente pudessem ser transcritas.

Foi feita análise de conteúdo segundo Bardin (1977). A autora organiza a análise de conteúdo em três fases cronológicas: (a) a pré-análise, que inclui leitura flutuante, escolha dos documentos, preparação do material que referenciará os índices e a elaboração de indicadores, (b) a exploração do material e (c) o tratamento, a inferência e a interpretação dos resultados. Dessa forma, o conteúdo coletado ao longo da pesquisa pôde ser devidamente analisado, e os resultados serão expostos no tópico seguinte.

\section{Resultados}

Com base nas falas dos servidores e gestores, foram elaborados oito fatores, sumarizados na Tabela 6. Verifica-se que os trabalhadores reconhecem a importância do programa para a sua qualidade de vida no trabalho (fator 2), relatam os benefícios oriundos da participação (fatores 4 e 5), contudo, revelam encontrar dificuldade em conseguir participar das atividades (fatores 1 e 7). 
Tabela 6. Percepção dos servidores e gerentes com relação ao PQVT

Fatores

1. Demanda de trabalho e dificuldade em ser liberado pelo gestor

2. Conhecimento e reconhecimento das ações do PGS

3. Atendimento da equipe do PGS e investimento de cada servidor para a manutenção do programa
Exemplo de fala

Frequência

"Tem essa dificuldade de se deixar as tarefas... porque tudo no Ministério é urgente, é prioridade, e muitas vezes a gente não consegue sair mesmo! Eu falo por mim, que eu tento, mas eu não consigo sair... deixar as coisas por fazer, porque é tudo muito urgente, tudo que chega na nossa mesa é urgente... então a gente acaba não priorizando a nossa qualidade de vida, e sim, priorizando apenas o trabalho".

"Mais gente poderia participar... é... em função da qualidade que é o trabalho do Geração Saúde, eu acho que mais pessoas poderiam participar e com certeza melhorar a vida de todo mundo".

"Eu sei que é um programa que visa melhorar a qualidade de vida do servidor do Ministério da Saúde".

“...Parabenizar a equipe, eu acho que 10 
Continuação tabela 6

Fatores

4. Descontração e integração

5. Bem-estar mental e físico

6. Sensibilização e conscientização

7. Dificuldades para permanecer no PGS (falta de estrutura física adequada, inadequação de horários)
Exemplo de fala

Frequência

"Porque a gente fica mais animado! Durante a ginástica, a gente brinca, a gente conversa também... é um momento de descontração também".

"Eu vejo o programa como também uma oportunidade de... de conhecer pessoas, de se integrar aos outros trabalhadores..."

"Yoga... me desestressava um pouco. Ajuda a segurar a onda... é... você vai mais tranquilo... você vai se autoeducando, e isso eu estou conseguindo também no alongamento".

"Eu sentia várias dores musculares e articulares, daí, ela me sugeriu fazer yoga, eu fui fazer e realmente... me fez um bem muito grande pra mim, melhorou as minhas dores, e por isso eu fiquei fazendo yoga quatro anos e meio, e por isso eu sinto falta e tenho vontade de voltar a fazer".

"Acho que o que poderia ser feito 5 também é trazer esse gestor para eles fazerem uns exercícios... porque vai que eles gostam, né? Daí eles vão ficar sensibilizados".

"Eu acho que, quando fosse assim... é... todo ano quando começasse o Geração Saúde, fosse feito assim... uma ampla divulgação, chamar... conversar com o servidor... conscientizar de que isso é importante e com as chefias também".

"E eu acho que é isso... a infraestrutura que deixa a desejar... o espaço físico, a questão do banheiro, a questão também um pouco dos equipamentos, e isso ajudaria bastante".

Adoro dançar... mas nunca consegui fazer a dança de salão por conta do horário, que pra mim é difícil... não consigo mesmo". 


\section{Discussão}

A realização dos três estudos, um quantitativo e dois qualitativos, possibilitaram uma análise detalhada da percepção dos diversos atores acerca do PQVT do Ministério da Saúde. O estudo quantitativo apresenta uma medida válida e precisa que avalia a percepção dos trabalhadores acerca da prática da ginástica laboral (GL). O estudo qualitativo aplicado aos funcionários permitiu compreender como os trabalhadores avaliam a GL e as outras atividades do programa, de modo que os resultados são complementares.

No estudo quantitativo, o fator que obteve a maior média foi o que trata dos benefícios da $G L$, e, nesse estudo qualitativo, os participantes ressaltam que a presença nas atividades traz benefícios para eles, e destacam, ainda, outros benefícios, como maior integração e descontração com os colegas de trabalho.

O fator com a menor média foi o que trata do método de trabalho, o que sinaliza a necessidade de aprimorar a maneira como as aulas são preparadas e conduzidas. $\mathrm{Na}$ pesquisa qualitativa realizada com os estagiários, verifica-se que esse é o fator que aparece em última posição, o que reforça a necessidade desse investimento na qualidade das aulas e maior acompanhamento dos supervisores de estágio. Conforme destacam Martins e Duarte (2000), o professor de GL deve diversificar as atividades a fim de que os trabalhadores não vivenciem nessa atividade a mesma rotina do ambiente de trabalho. $\mathrm{O}$ profissional responsável por tais atividades deve destinar um tempo para esclarecer as dúvidas relacionadas com aspectos físicos, de saúde e psicológicos, além disso, tal postura profissional fortalece os vínculos estabelecidos com os trabalhadores.

Os trabalhadores pesquisados demonstram conhecimento das atividades oferecidas pelo órgão e mostram interesse em participar mais ativamente, contudo, pontuam que a demanda de trabalho dificulta a permanência nas atividades. Walton (1973) afirma que a quantidade de trabalho é um aspecto central na compreensão da qualidade de vida no trabalho.

\section{Considerações finais}

O presente trabalho respondeu a uma demanda do Ministério da Saúde e avaliou de maneira ampla o Programa de Qualidade de Vida no Trabalho do referido órgão. As atividades de ginástica laboral são importantes em um PQVT, pois auxiliam na prevenção de doenças ocupacionais (Oliveira, 2007), na redução dos acidentes de trabalho e promovem a integração no ambiente de trabalho (Martins \& Duarte, 2000); todavia, um programa de qualidade de vida no trabalho não deve se restringir a tais ações. Sob o risco de se ter uma visão reducionista do trabalhador.

A existência de um PQVT na organização pesquisada sinaliza uma preocupação com o trabalhador no ambiente de trabalho; a despeito disso, são necessários aprimoramentos. Recomenda-se que a qualidade de vida no trabalho seja tratada de maneira preventiva e com uma visão contra-hegemônica, que sustenta que a QVT é uma atribuição de todos os atores organizacionais e que deve haver uma busca pelo bem-estar, pela eficácia e pela eficiência no ambiente organizacional. Essa abordagem se fundamenta na ergonomia da atividade e busca remover os causadores de mal-estar no trabalho considerando três dimensões interdependentes, condições, organização e relações socio-profissionais (Ferreira, et al., 2009).

Dentre os aspectos a serem considerados em um PQVT, estão a participação dos trabalhadores nas decisões que afetam o seu 
desempenho, a reestruturação das tarefas para que o trabalhador tenha mais liberdade de ação e sistemas de recompensa justos que considerem o esforço e a adequação do ambiente de trabalho às necessidades individuais (Pilatti \& Bejarano, 2005).

No estudo quantitativo, foi elaborada uma escala com qualidade psicométrica adequada para aferir a percepção dos trabalhadores acerca da GL, pois os coeficientes de confiabilidade encontrados são satisfatórios, com exceção do fator método de trabalho; assim, recomenda-se que essa dimensão seja ampliada. Os trabalhadores avaliaram positivamente os benefícios da ginástica laboral, sendo que estes não se restringem apenas ao trabalho, mas promovem o bemestar. Um ponto que merece ser aprimorado é o método de trabalho, que compreende o ambiente utilizado para a realização das atividades, a música e a duração das aulas.

Espera-se que o presente trabalho tenha servido de subsídio para a organização pesquisada na definição das próximas ações relacionadas ao seu PQVT. Considerando o objetivo do estudo de avaliar a percepção dos trabalhadores, uma expectativa que foi externalizada por eles é a de que o programa não acabasse. Dessa forma, anseia-se que outras pesquisas possam ser desenvolvidas com a finalidade de fortalecer e disseminar os conhecimentos sobre qualidade de vida no trabalho.

Polyanna Peres Andrade

Mestra em Psicologia Social, do Trabalho e das Organizações pela Universidade de Brasília. Realiza atividades em Psicologia do Trabalho, Universidade de Brasília - DF - Brasil.

E-mail: polyperes@gmail.com

Heila Magali da Silva Veiga

Doutora em Psicologia Social, do Trabalho e das Organizações pela Universidade de Brasília, Docente da Universidade Federal de Uberlândia, Minas Gerais, MG - Brasil.

E-mail: heila.veiga@gmail.com

Endereço para envio de correspondência:

SQN 311 BI. F apto. 403 Asa Norte, Brasília - DF CEP: 70757-060 


\section{Referências}

Albuquerque, L. G. de, \& Limongi-França, A. C. (1997). Estratégias de recursos humanos e gestão da qualidade de vida no trabalho: o stress e a expansão do conceito de qualidade total. Revista de Administração, 33(2), 40-51.

Bardin, L. (1977). Análise de conteúdo Lisboa: Edições 70.

Fernandes, E. C. (1996). Qualidade de vida no trabalho: como medir para melhorar. Salvador: Casa da Qualidade.

Fernandes, E. C., \& Gutierrez, L. H. (1988, out./dez.). Qualidade de vida no trabalho: uma experiência brasileira. Revista de Administração, USP, 23(4), 29-38.

Ferreira, M. C. (2006). Qualidade de vida no trabalho (QVT). In A. D. Cattani \& Holzmann, L. (Org.), Dicionário de Trabalho e Tecnologia. Porto Alegre, RS: Editora da UFRGS.

Ferreira, R. R., Ferreira, M. C., Antloga, C. S., \& Bergamaschi, V. (2009). Concepção e implantação de um programa de qualidade de vida no trabalho no setor público: o papel estratégico dos gestores. Revista de Administração, 44(2), 147-157.

Guimarães, V. N. (1998). Qualidade de vida no trabalho e introdução de inovações tecnológicas: estudo comparativo de casos na indústria mecânica de Santa Catarina. Revista de Ciências da Administração, 1(0), 77-86.

Hackman, J. R., \& Oldham, G. R. (1975). Development of the Job Diagnostic Survey. Journal of Applied Psychology, 2(60), 111-124.

Lima, D. G. (2004). Ginástica laboral: metodologia de implantação de programas com abordagem ergonômica. Jundiaí, SP: Fontoura.

Limongi-França, A. C., \& Zaima, G. (2002). Gestão de qualidade de vida no trabalho - GQVT. Manual de Gestão de Pessoas e Equipes: Estratégias e Tendências. São Paulo: Gente.

Marques, A. L., Guimarães, R. S., \& Adorno, R. D. (2008). A LDB/96 e a qualidade de vida no trabalho: com a palavra os docentes da rede pública de Belo Horizonte. Revista de Ciências da Administração, 10(20), 72-94.

Martins, C. O., \& Duarte, M. F. S. (2000). Efeitos da ginástica laboral em servidores da Reitoria da UFSC. Revista Brasileira de Ciências e Movimento, 8(4), 07-13.

Mônaco, F. de F., \& Guimarães, V. N. (2000). Gestão da qualidade total e qualidade de vida no trabalho: o caso da gerência de administração dos correios. RAC, 4(3), 67-88.

Monteiro, J. K., Maus, D., Machado, F. R., Pesenti, C., Bottega, D., \& Carniel, L. B. (2007). Bombeiros: um olhar sobre a qualidade de vida no trabalho. Psicologia: Ciência e Profissão, 27(3), 554-565.

Nadles, D., \& Lawler, E. (1983). Quality of work life: Perspectives and directions. Organizatinal Dynamics, 11(3), 20-30.

Oliveira, J. R. G. (2007). A importância da ginástica laboral na prevenção de doenças ocupacionais. Revista de Educação Física, 139(1), 40-49.

Pasquali, L. (2005). Análise fatorial para pesquisadores. Brasília, DF: LabPAM.

Pilatti, L. A., \& Berjarano, V. C. (2005). Qualidade de vida no trabalho: leituras e possibilidades no entorno. In A. G. Gonçalves, G. L. Gutierrez \& R. Vilarta (Orgs.), Gestão da qualidade de vida na empresa (pp. 85-104). Campinas, SP: IPES Editorial.

Tolfo, V. C., \& Piccinini, V. C. (2001). Qualidade de vida no trabalho: disjunções entre a teoria e a prática. $R A C$, 5(1), 165-193.

Vasconcelos, A. F. (2001). Qualidade de vida no trabalho: origem evolução e perspectivas. Cadernos de Pesquisa em Administração, 8(1), 23-35.

Walton, R. E. (1973). Quality of working life: What is it? Sloan Management Review, 15(1), 11-21.

Werther, W. B., \& Davis, K. (1983). Administração de pessoal e recursos humanos. São Paulo: McGraw Hill do Brasil. 